\title{
Pervivencia de mitos históricos en la formación del Profesorado de Educación Inicial, Primaria y docentes en Argentina
}

\section{Survival of historical myths in trainee teachers in early childhood and primary education, and teachers in Argentina}

Armas, María Celeste; de la Montaña Conchiña, Juan Luis

María Celeste Armas celemx.ca@gmail.com Inst. Superior de Formación Docente J. J. de Urquiza, Argentina

\section{(iD Juan Luis de la Montaña Conchiña jmontana@unex.es Universidad de Extremadura, España}

Clio \& Asociados. La historia enseñada Universidad Nacional del Litoral, Argentina

ISSN: 2362-3063

Periodicidad: Semestral

núm. 32, 2021

clio@fhuc.unl.edu.ar

Recepción: 03 Febrero 2021

Aprobación: 17 Mayo 2021

URL: http://portal.amelica.org/ameli/jatsRepo/111/1112174005/ index.html

DOI: https://doi.org/10.14409/cya.v0i32.10067
Resumen: A fines del siglo XIX el surgimiento de los Estados Nación ha demandado a la Historia un rol legitimador en la conformación identitaria y en la consolidación de sus orígenes, dando por resultado mitos, prácticas y discursos funcionales a él. En este escenario, la escuela siempre fue un lugar propicio para acompañar los fundamentos nacionalistas materializados en las conmemoraciones, el curriculum, manuales escolares o actos rituales. En contexto, las diferentes concepciones de la Historia en general, y los ideales nacionalistas en particular, toman especial relevancia en la formación del profesorado y en el trabajo docente. En Argentina, y en gran parte del mundo, las efemérides perviven inmutables, instaurando ideas románticas y mitos históricos sobre la Historia nacional que perduran en la formación del profesorado y sus primeros años en ejercicio. El presente trabajo busca visibilizar resultados parciales de una investigación más amplia que reconoció aquellas concepciones míticas y románticas arraigadas en maestros y estudiantes del profesorado de Educación Inicial (infantil) y Primaria.

Palabras clave: mitos históricos, nacionalismo, formación del profesorado, conmemoraciones.

Abstract: Towards the end of the 19th century, in much of the world, the emergence of the Nation States has demanded a legitimizing role from History in the conformation of a collective identity and in the search for the consolidation of its origins, resulting in myths, practices and functional speeches to him. In this scenario, the school was always a propitious place to accompany the nationalist foundations materialized in the commemorations, the orientations of the curriculum, school manuals or ritual acts. In this sense, the different conceptions of History in general, and nationalist ideals in particular, take on relevance in the training of teachers and in teachers. In Argentina, and the world, the ephemeris survive as immutable, establishing in the collective imagination certain romantic ideas and historical myths about the national history, which even last until the stage of initial teacher training and their first years of work. This paper seeks to make visible the partial results of a broader investigation that came close to recognizing those 
mythical and romantic conceptions most deeply rooted in the trainee teachers in early childhood and primary education, and teachers.

Keywords: historical myths, nationalism, teacher training, commemorations.

\section{Introducción}

Numerosos autores han investigado y analizado el uso de la Historia desde la esfera política y, por ende, educativa. Como menciona De Baets 'It is history that can be abused, not the past' (2013:20). Si bien cada Nación lleva consigo una Historia en torno a sus hitos y epopeyas, hay ciertos mecanismos en la sistematización y comunicación de sus discursos que se repiten a nivel global, considerando que, como refiere MacMillan, la Historia provee parte del combustible para la construcción del nacionalismo (2009). Podríamos ir más lejos, como hace Tertrais (2017:43) al señalar que "si la nación se alimenta de la Historia, el nacionalismo la devora”. La manipulación de ciertos hechos históricos para fines legitimadores lleva a la construcción de ciertos mitos que, con el tiempo, podrían generar la pérdida de credibilidad en la historiografía a lo largo de los años (De Baets, 2013).

En este escenario la escuela aparece como una institución aliada del estado para la transmisión de los discursos históricos nacionalistas y, en este sentido, no debemos olvidar que el estado es el que perfila el curriculum, las materias, contenidos y criterios de cientificidad (Pérez, 2007). En el caso de América Latina, muchos de los hitos históricos encuentran su origen en los movimientos independentistas y a partir de allí se busca crear una idea unificadora de nación mediante las conmemoraciones y los actos escolares. Esta manera de trabajar la Historia, iniciada a principios del siglo XIX y prolongada hasta el siglo XXI, da lugar a la pervivencia de mitos en el imaginario colectivo que simplifican de manera relevante aspectos de la Historia disciplinar.

De esta manera, el objetivo de este trabajo consiste en visibilizar algunos de los mitos que más perduran en el imaginario de estudiantes y docentes de Educación Inicial (infantil) y Primaria en la ciudad Río Cuarto, Córdoba, Argentina. En el artículo se presentarán resultados parciales que forman parte de una investigación más amplia, realizada en el marco de trabajo final de Máster, cuyo objetivo general fue identificar si estos mitos simplificadores se reproducían tanto en la formación del profesorado de Educación Infantil y Educación primaria, como en docentes en ejercicio, cuáles estaban más arraigados en el imaginario colectivo de estudiantes y docentes, y finalmente, qué relación guardaba este hecho con sus trayectorias educativas.

\section{La conmemoración y el mito en el uso de la Historia}

Entre mediados y finales del siglo XIX en muchos países del mundo comienza el proceso de consolidación de Estados Nacionales, y con ellos, la necesidad de forjar una historia que acompañe a los grandes héroes, sus grandes hazañas, sus gloriosas conquistas, y, que construya esa identidad colectiva dando vida a esa "nación". En palabras de MacMillan: 
Las comunicaciones rápidas, una mayor alfabetización y urbanización, y por encima de todo, la idea de que es bueno y correcto verse como parte de una nación, además, que debe tener su propio estado dentro de su propio territorio, todo ello concluyo en la gran oleada de nacionalismo que sacudió a Europa en el siglo XIX y al mundo en general. (MacMillan, 2009:58)

Hay una realidad que trasciende a cualquier particularidad histórica, "de las muchas maneras que tenemos de definirnos a nosotros mismos, la nación, al menos en los dos últimos siglos, ha sido una de las más atrayentes" (Ibídem:57), de manera tal que la Historia en el contexto escolar da cimientos a la construcción de la ciudadanía y sentimientos nacionalistas.

Cada Nación y cada cultura necesita un origen, el renombrado "mito de los orígenes" que tanto resuena entre los historiadores. Ese origen, esa Historia, desde siempre fue y será puesta al servicio de la legitimidad y la lealtad a esa Nación o ese grupo.

Controlar el pasado "ayuda a dominar el presente y a legitimar dominaciones e impugnaciones” (Ferro, 1981:5). Engañar en el uso de la Historia siempre genera un daño, aunque no haya víctimas directas, la historiografía comienza a perder credibilidad y estimula la creencia de mitos y propagandas históricas que afectan a la sociedad, en palabras de De Baets:

Abuses threaten that confidence and, therefore, the authority and efficiency of professional historical writing. They engender social costs in terms of the declining credibility of the historical profession and lower the overall quality of the historical discourse. They stimulate beliefs in historical myths and propaganda or induce amnesia concerning previously known history. The harm done to historical writing is a social harm. (De Baets, 2013:25)

El autor distingue entre el abuso y el uso irresponsable de la Historia, entendiendo que 'the abuse of history is its use with intent to deceive. The irresponsible use of history is either its deceptive or its negligent use' (Ibídem:24). Es decir, el abuso de la Historia es cuando se usa con una intención predeterminada de engañar a otros, mientras que el uso irresponsable de la historia puede generar engaño o negligencia sin intención en muchas ocasiones.

$\mathrm{Al}$ referirse a las conmemoraciones escolares, Mario Carretero afirma que "las personas y las sociedades humanas hacemos cosas con la Historia" (2019:2), claro está que cada nación construye su legitimidad con sus figuras, sus voces, sus silencios y sus raíces; sin embargo, suelen repetirse mecanismos y maneras de usar el pasado, de manera tal que, como mencionaba Benedetto Croce a principios de siglo XX, "la historia plantea los problemas de su tiempo más que los de la época que es objeto de estudio” (cit. en Ferro, 1981:7).

Las conmemoraciones, de alguna manera "contribuyen al proceso continuo de creación de mitos que permiten a la Historia crear, modificar o sancionar los significados públicos unidos a acontecimientos históricos considerados como merecedores de una celebración de masas" (Trouillot, 2017:99). MacMillan, por su parte, recuerda que somos los historiadores los encargados de cuestionar e incluso desmontar los mitos nacionales. La Autora retoma a Howard (2006) para explicar que esta desmitificación es indispensable, entendiendo que "tal desilusión es parte necesaria del crecimiento y la pertenencia a la sociedad adulta" (cit. en MacMillan 2009:31). 
En este escenario, entonces, las celebraciones se crean, y esta creación es parte integrante del proceso de producción histórica. Las celebraciones combinan las dos caras de la historicidad. "Imponen un silencio sobre los acontecimientos que ignoran y llenan ese silencio con narrativas de poder sobre el acontecimiento que conmemoran" (Trouillot, 2017:101).

Claramente también existe un interés por parte del sistema educativo de mantener y alimentar ciertas narrativas que fortalezcan el ideal nacionalista (Saiz, 2017 cit en Montaña y Rina, 2019). De manera tal que "la vitalidad del nacionalismo en el profesorado en formación, en contextos progresivamente más trasnacionales, es un elemento de reflexión fundamental, en tanto que serán agentes y correa de trasmisión de los valores y mitos nacionales en el sistema educativo" (Montaña y Rina, 2019:96).

Entendiendo al nacionalismo como el conjunto de creencias ideológicas, prácticas y rutinas que reproducen el mundo de los Estados-Nación (Billig 1998), entendemos que tanto el mito como el rito toman vital importancia en la creación y transmisión de una identidad colectiva nacional. Como menciona la investigadora mexicana Margarita Quezada (2009:196) existe una vinculación entendiendo que el mito construye "una historia que relata los orígenes, reales o ficticios, del hombre actual, creando así un tipo de conexión con sus ancestros, verdaderos, imaginarios, inventados o elegidos, desde la historia nacionalista". La construcción de una identidad colectiva a través de mitos fundantes funcionales a la historia del origen de un Estado Nación es una práctica estudiada y mecanizada aún en el siglo XXI.

El pasado tiene una dimensión mítica y para ir más allá de su mera construcción y trasladarlo a las aulas es preciso insistir en la creación y recreación de personajes, acontecimientos que, normalmente, se caracterizan por sobreponerse al otro, al contrario. Como dice Tertrais (2017), la práctica totalidad de mitos y sus símbolos asociados se construyen partiendo de un error que consiste en extraer un acontecimiento o personaje de su contexto y hacer de ello un símbolo. La Historia entendida como un producto maleable, es el medio perfecto en el que construir esos referentes simbólicos. Del mismo modo, los personajes convertidos en mitos nacionales, pueden, y de hecho lo hacen, transformarse en una reivindicación política. Como señala Hunt (2019), los monumentos, los mitos, reclaman su espacio en la Historia. La fabricación de estos mitos, acompañados de personajes y acontecimientos simbólicos y recurrentes no son cuestionados ni por los modelos educativos al uso, ni por el conjunto de la sociedad.

Nos situamos, por tanto, ante una visión nacionalista de la Historia escolar que cimenta y consolida identidades colectivas excluyentes al tener como eje discursivo el relato nacional, apoyándose en magnificar las diferencias entre "nosotros" y los "otros" (Miralles y Gómez, 2017). Sin embargo, no hablamos de nuevas realidades. Éste es un problema ampliamente extendido, reproducido y gestionado sin rubor alguno por escuelas y profesionales de la disciplina y por los sistemas educativos. Así, en el contexto internacional, hay casos como el de los EEUU en los que las diferentes narrativas, transformadas y adecuadas a diferentes contextos históricos siempre buscaron reforzar el sentimiento de unidad e identidad colectiva, pero en el caso americano asociado a las ideas de progreso y desarrollo (Appleby, Hunt, Jacob, 2000). La construcción de mitos entendidos como elementos que refuerzan las identidades colectivas hicieron 
bascular, por ejemplo, la Historia de Francia entre la barbarie y la civilización hasta concluir que "nos vrais ancêtres sont les Gallo-romanins" (Citron, 1984:16; Citron, 2017), un planteamiento histórico que no hacía más que confirmar el curriculum y los manuales escolares establecidos en la III República, en un intento de evitar los socialmente demoledores "paniques identitaires" como señalan Cock y Meiran (2017). Los casos podrían multiplicarse. Es evidente, por tanto, que las inercias y derivas nacionalistas en las que se encuentran los actuales estados reflejan perfectamente el pensamiento, la idea que se posee sobre la disciplina: la Historia debe promover el patriotismo a partir de la advocación de tiempos pasados, personajes y acontecimientos que fueron el germen o la semilla de las actuales naciones (Miralles y Gómez, 2017). En este sentido, habría que insistir en un obstáculo más con el que se encuentra la Historia como materia escolar que se traslada a las aulas, y es que ésta no suele estar sujeta a crítica por parte de los docentes. El problema, que arranca en la Historia aprendida en etapas escolares y que no es cuestionada ni revisada posteriormente en la formación universitaria como futuros docentes, ha sido objeto de numerosos estudios (Egan 1997; Carretero y López, 2009; Montaña y Rina, 2019).

Las identidades colectivas, creadas y soportadas por y sobre mitos nacionalistas en los que caben una nutrida presencia de los más variados personajes históricos, se ven reforzadas en los entornos escolares y especialmente fuera de ellos por la abundancia de consignas y los más variados elementos. A este respecto resulta cada vez más habitual encontrar en los medios de comunicación de masas, internet, redes sociales expresiones habituales centradas sobre "nosotros", lo "nuestro", en un claro ejercicio de deixis patriótica tal y como la ha definido Billig en su propuesta de lo que denominó como nacionalismo banal (1998). Elementos que pueblan los discursos políticos y que emanan de diferentes entornos incluyendo núcleos familiares y otros contextos cotidianos están presentes en las aulas y forman parte la experiencia educativa cotidiano del alumnado.

\section{Las "independencias" latinoamericanas como fuentes de conmemoraciones}

La expresión que refiere a los "usos incorrectos del pasado" fue originalmente utilizada por Habermas en la década del ' 80 y retomada por numerosos autores para referirse a la distinción entre el pensamiento historiográfico propio de los especialistas de la disciplina, y aquellas eventuales utilizaciones que se hace de la Historia en el ámbito público (Carretero \& Kriger, 2012). Entendemos que la Historia fue, por excelencia, la asignatura escolar encargada -junto con la Geografía- de legitimar los orígenes de los estados nacionales que emergen en América latina en el siglo XIX. En esta línea, el uso que se hizo (y se hace) de la Historia -correcto o incorrecto- no sólo tendrá implicancias en los discursos políticos, sino que también entrará en las aulas de cada tiempo generando una relación casi indisociable entre política, historia y educación.

Al igual que el caso mexicano, la mayoría de los países latinoamericanos en los períodos de fundación nacional, "directamente relacionados con la culminación de la guerra de la independencia y la revolución, el Estado y los grupos sociales, fijaron su mirada en la educación histórica con la idea de hacer uso de ella para hacer patria y formar ciudadanos" (Arteaga Castillo y 
Camargo Arteaga, 2011:372). En este punto el estado se sirve de herramientas para controlar el pasado y legitimar el presente, de manera que "las sociedades de pasado colonial comienzan a descolonizar su historia, pero a menudo con los mismos instrumentos del colonizador, construyendo una historia completamente inversa" (Ferro, 1981:6).

En continuidad con estas ideas, se busca contextualizar la manera en que desde principios del siglo XIX la elite criolla (hijos de españoles nacidos en territorio americano) construyen un pasado común y homogeneizador que, si bien resaltan sentimientos nacionalistas y dan suma importancia a la independencia, siguen generando omisiones, silencios y lagunas, al consolidarse como un relato lineal, incuestionable y repleto de hazañas y grandes glorias de hombres convertidos en semidioses.

Más que preocuparnos, nos ocupa entender los motivos por los cuáles esta construcción histórica "oficial" se instala de manera tal que llega hasta nuestros días trascendiendo generaciones. A la vez, ésta se desarrolla de manera paralela a una disciplina histórica que no perduró estática, como sí lo hizo la historia conmemorativa, sino que tuvo (y tiene) intentos de trabajar desde una mirada crítica el relato histórico al interior de las aulas. Como plantean las investigadoras de la Universidad Pedagógica Nacional de México, Belinda Arteaga Castillo y Siddharta Camargo Arteaga (2011:372) "el discurso académico sigue sin poder encontrar los canales de comunicación adecuados para llegar a la sociedad en su conjunto".

Como ya se ha mencionado, la escuela, en tiempos de la conformación del Estado nación (mediados y finales del siglo XIX) contaba con dos medios específicos para transmitir esta historia oficial: los manuales escolares por un lado y los actos conmemorativos por el otro. La enseñanza de la historia argentina, desde aquellos tiempos y durante más de cien años, "transmitió un relato genealógico de la nación dando a conocer un panteón de próceres y haciendo cumplir rituales de homenajes a los héroes y epopeyas de la patria en actos escolares que eran liturgias de carácter laico", puesto en palabras de María Paula González (2008:57). Parte de estos elementos se configuran, por ejemplo, en las obras históricas como la de Bartolomé Mitre -Historia de Belgrano y de la Independencia argentina (1857)- cuya "prosa histórica ha gozado de una excepcional aceptación hasta hace pocos años, lo que ha incidido en su difusión como el vehículo más eficiente de los contenidos históricos del nacionalismo Argentino" (Mejía, 2007:99) Por otra parte, contribuyó también a la difusión de esta mirada romántica de la historia nacional, la obra novelada de Vicente Fidel López "La gran Semana de Mayo" (1885), de aquellas líneas emergen muchas de las ideas románticas y míticas que aparecen en nuestras aulas y que ampliaremos más adelante.

Un elemento que ayuda a la perdurabilidad de ciertos mitos que giran en torno al discurso conmemorativo es el acto escolar, acto de carácter "ritualístico" como mencionan los especialistas en la temática (Amuchástegui, 1995; Castillo y Allori, 2005; Carretero, 2007; González, 2008; Guillen 2008; Arata 2014; Guidi, 2015; Parellada, 2019), y cuyo inicio data de 1887 cuando Pablo Pizzurno organiza los festejos conmemorativos del 25 de mayo en el propio establecimiento educativo por primera vez. Esta idea fue aceptada por la elite gobernante de la época y en los años sucesivos la participación infantil fue uno de los 
aspectos centrales del programa. Como ya mencionamos, prácticas como los actos escolares, la ceremonia de izar la bandera o formar fila y tomar distancia con el brazo respecto del compañero, son llevadas a cabo por los niños de hoy tal cual lo hicieron sus bisabuelos. El ritual moldea de esta manera las identidades (Amuchástegui, 1995).

Como todo ritual, los actos escolares siguen una serie de pasos que en la actualidad no distan mucho de los propuestos en 1887, y en donde el silencio, la postura y el homenaje a los próceres cobran significación como conducta patriótica en un contexto determinado. Esta manera ritual de abordar las conmemoraciones influye en la conformación de estas ideas simplificadoras y míticas construidas en torno al discurso oficial y arraigadas por generaciones en la sociedad argentina. Según Mario Carretero y Miriam Kriger (2012) la consecuencia más inmediata que ello genera es la existencia de dos diferentes fuentes y dispositivos didácticos para la enseñanza del pasado "común", la romántica conmemorativa y la histórica critica (arraigado a lo disciplinar).

\section{Mitos y simplificaciones en el discurso histórico argentino reproducidos en el Profesorado de Nivel Inicial (infantil) y Nivel Primario}

Como se ha mencionado en apartados anteriores, la trayectoria educativa de quienes se forman para enseñar Historia y Cs. Sociales tendría cierta incidencia en la relación que se establece con ese saber y con la concepción de este a lo largo de su carrera. La formación docente de nivel superior en Argentina presenta como gran fortaleza la estructura de las prácticas y residencias, las cuales, en palabras de Cristina Davini (2015:33) "movilizan contenidos de otras áreas curriculares". Sin embargo, según informes realizados por la Dirección General de Estudios Superiores (DGES) de la provincia de Córdoba, se visualizaron en el último tiempo ciertas dificultades en los estudiantes de profesorado para recuperar contenidos propios de las disciplinas específicas, y así, establecer relaciones con la planificación y la práctica (Abrate, 2020). Si bien los estudios sobre el abordaje de Cs. Sociales en la formación docente representan un campo poco abordado, los diseños curriculares nos permiten observar que los contenidos básicos sugeridos en nivel superior (DC-Córdoba 2015-2020) giran en torno al aprendizaje de hechos aislados de la Historia Argentina o a la enseñanza de las diferentes corrientes de Historia de las políticas educativas específicamente, careciendo de propuestas, herramientas y estrategias que habiliten a futuros docentes a prensar un conocimiento didáctico de los contenidos propios del área durante el proceso de formación.

Por otro lado, los diseños curriculares de los niveles para los cuales el profesorado se prepara (inicial y primaria) presentan según Carretero y Kriger (2012), una gran contradicción entre la manera en que se abordan las efemérides y la manera en que se desarrolla el contenido de Ciencias Sociales, careciendo de una mirada crítica y coherente respecto del pasado histórico. Según Carretero y López (2009), por otra parte, muchos de los mitos del discurso histórico se originan en estos niveles, atendiendo a las etapas de comprensión de la narrativa histórica mítica y romántica que atravesamos en la infancia. 
En la cotidianeidad de las aulas - tanto de la formación del profesorado, así como de infantil y primaria- aparecen en reiteradas ocasiones ciertos mitos históricos arraigados al imaginario colectivo e ideas simplificadoras o erróneas frente al proceso histórico en general, que se hacen evidentes al momento de trabajar las efemérides que presenta el calendario escolar. Entre los mitos que más suelen reproducirse a simple vista encontramos: el supuesto reparto de escarapelas por "French y Berutti" en Plaza de Mayo, celebrando románticamente el "primer gobierno patrio". Hecho que en realidad responde a la historia de dos sujetos con ideales independentistas -mencionados en algunos documentos como "los chisperos" por introducir la idea de la revolución en los sectores populares de la sociedad colonial y cargar armas de fuego, conformando lo que hoy llamamos un grupo de choque- quienes en realidad durante las jornadas de mayo repartían insignias que marquen a quienes votarían a favor de la renuncia del virrey. Lo hicieron repartiendo cintas de colores, detalle que la historia no pudo aún confirmar si eran blancas o rojas.

Por otro lado, también es común oír repetir que la "firma de independencia" en el Congreso de Tucumán en 1816 significó la liberación absoluta y el inicio de la actual "conformación del territorio argentino". Al trabajar esta conmemoración, lo que muchos y muchas dejan pasar es que no todas las provincias asistieron al Congreso de Tucumán. La Liga Oriental (Santa Fe, Entre Ríos, Corrientes y la Banda Oriental) estaban enfrentada con Buenos Aires buscando la independencia propia respecto del centralismo capitalino. Por lo que la "declaración de la independencia" no indica la formación de un Estado unificado, ni da los limites políticos a la Argentina actual, serán casi 40 años después de una guerra civil que se logrará cierta centralización.

En lo respecta al tercer mito, se repite aún en el siglo XXI y desde hace ya varias generaciones, que Manuel Belgrano se sentó a la orilla del río Paraná y mirando al cielo decidió que aquellos serían los colores de la bandera argentina -expresado por Juan Bautista Alberdi en una versión novelada de la guerra de la independencia denominando a nuestra bandera como "hija del cielo"-. Si bien el origen de los colores de la bandera es un tema controvertido sobre el cual no se logra un fundamento unificado entre los historiadores, lo cierto es que no necesariamente nuestra insignia nacional quedo librada únicamente a un momento de romanticismo reflexivo. Entre las diversas teorías, muchos investigadores barajan la posible relación entre los colores celeste y blanco, provenientes de la escarapela y las insignias que representaban en aquella época a la Monarquía Borbónica del Rey de España Carlos III en 1771.

En relación a las ideas simplificadoras de ciertos procesos históricos que habilitan a un mal uso de la historia en reiteradas ocasiones, la más común entre estudiantes de profesorado y docentes en ejercicio, es la asociación del "20 de junio" -aniversario de fallecimiento de Manuel Belgrano en 1820- a la creación de la bandera argentina - 17 de febrero de 1812-, esto podría deberse a que el calendario escolar denomina dicha efeméride como "El día de la bandera". Esta connotación genera confusión ya que se conmemora un hecho ocurrido casi una década atrás en el contexto de las guerras independentistas.

Otra idea que es recurrente entre estudiantes y docentes es la creencia que a la llegada de Colón en 1492 no sólo se "descubre" América -isla de Santo Domingo-, sino que se arriba también a las grandes civilizaciones americanas, creyendo como 
procesos contemporáneos la conquista del imperio Inca y el imperio Azteca. De esta manera, la "Conquista de América" se traduce en el discurso como un hecho unificado, acrítico, sin disociación de las diferentes corrientes conquistadoras y dejando silenciados procesos como las acciones de Pizarro y Cortés -perdidos en la línea temporal- cuyas particularidades son importantes para comprender muchos aspectos de nuestro presente.

Finalmente, al igual que ocurre con la conmemoración del 20 de junio, el 17 de agosto deja confusiones en el ideario colectivo. San Martín cruza los Andes luego de la firma de independencia de las Provincias Unidas del Río de la Plata, con el fin de liberar Chile y Perú. En las aulas, circula la idea de que el Cruce de los Andes forma parte de nuestro propio proceso independentista, el cruce de los Andes genera una doble confusión ante los estudiantes: por un lado, muchos creen que se cruza los Andes un 17 de agosto -sin reparar en la muerte del General- y, por otro lado, se considera previo a nuestra firma de independencia. Son muchos los detalles en los que las "conmemoraciones" no reparan en el ámbito escolar.

Estos mitos e ideas equívocas que se escuchan en las aulas de formación docente son la que decidimos sistematizar, a los fines confirmar metodológicamente su pervivencia en el imaginario colectivo y conocer cuál de ellas perduraba con mayor fuerza.

\section{Metodología}

La investigación contó con una muestra no probabilística de 61 encuestados, en el total se consideran estudiantes de los profesorados de Educación Inicial (infantil) y Educación Primaria, y docentes en ejercicio de ambos niveles educativos -y de tres instituciones diferentes- de la ciudad de Río Cuarto, Argentina. Se apostó, a una triangulación "entre-métodos" (Aguilar \& Barroso 2015:75) combinando metodologías cuantitativas y cualitativas en la misma investigación, visibles en los diferentes apartados que conforman el cuestionario, para recabar información contrastando los resultados y analizando coincidencias y diferencias de una misma unidad de análisis.

Se ha seleccionado el cuestionario como instrumento de recogida de datos con preguntas cerradas y abiertas según la información que se buscaba obtener. Un primer apartado consistía en los datos personales (conservando el anonimato), y el segundo apartado -el cuál toma relevancia para el objetivo que apunta mostrar este articulo- constaba de dos tipos de preguntas cerradas que buscaban conocer si existen ideas simplificadoras o mitos arraigados en los encuestados, y si existen, cuáles son los que más se repiten. Para esto, la primera pregunta constó de 5 ítems referentes a las conmemoraciones más tradicionales, con opción de respuestas múltiple entre las que se incluían algunas respuestas más orientadas a la mirada crítica-reflexiva que propone la historia como disciplina, y otras orientadas a las ideas más simplificadoras o mitos que suelen repetirse de generación en generación y perviven en los relatos nacionalistas. La segunda pregunta de este apartado tenía por delante el mismo objetivo y constaba de un listado de afirmaciones en las cuales los encuestados contestaron estar "en acuerdo" o "en desacuerdo", permitiendo observar si predomina una visión más crítica de la Historia o si se conserva la mirada romántica de los hechos. 


\section{Resultados}

Luego de confirmar que efectivamente pervivían en estudiantes de profesorado y docentes en ejercicio ciertos mitos que dan a lugar a la reproducción de ideas simplificadas de la historia, se buscó identificar cuáles son las ideas que más se repiten en el imaginario de los estudiantes y docentes de nivel infantil y primario. Si bien en muchos casos el sistema de procesamiento de datos en SPSS no indicaba como mayoritario o diferencialmente significativo ciertos resultados respecto del porcentaje muestral, es importante entender que desde una mirada cualitativa significa mucho saber que determinada cantidad de docentes conciben la historia de aquella forma, ya que cada encuestado representa un maestro (o un futuro maestro) a cargo de un promedio de 20/30 estudiantes que son ciudadanos argentinos en formación. En lo que respecta al primer apartado del cuestionario, comenzamos analizando la pregunta en la cual se debía "indicar qué afirmación consideraban correcta”, es importante resaltar que este punto era de opción múltiple, por lo que el porcentaje que aparece en cada de mito es representativo del total de los encuestados, por lo que debe analizarse cada premisa de manera individual respecto a la totalidad de la muestra.

Podemos observar lo siguiente:

Tabla 1.

\begin{tabular}{|l|l|l|}
\cline { 2 - 3 } \multicolumn{1}{c|}{} & Respuestas por el SI & \% total de encuestados \\
\hline Los colores de la Bandera Argentina responden a los colores del cielo & 31 & $50 \%$ \\
\hline French y Berutti repartieron escarapelas en Plaza de Mayo el 25 de Mayo de 1810 & 30 & $48,4 \%$ \\
\hline
\end{tabular}

Mitos afirmados según el total de los encuestados.

La mitad de la muestra consideraron que los colores de la bandera argentina se deben a los colores del cielo. Por otro lado, el 48,4\% de la muestra (casi la mitad) afirman que French y Berutti repartieron escarapelas el 25 de mayo. Es considerablemente menor quienes entienden que los límites políticos actuales de lo que hoy conocemos como "Argentina” se conforman en 1816.

En lo que respecta al apartado en el que se debía responder si estaban de acuerdo o en desacuerdo con determinadas afirmaciones, pudimos identificar algunas ideas erróneas respecto al proceso histórico en sí mismo. Preguntas en donde se da mayoría de respuestas "de acuerdo" fueron analizadas mediante tablas de frecuencias en SPSS. Es importante insistir que, si bien en muchas de las afirmaciones la prueba de Chi Cuadrado no arroja resultados cuantitativamente significativos, desde una mirada cualitativa creemos que la cantidad de encuestados que siguen dichas creencias sí toman relevancia y por esa razón se mencionan a continuación: 
Tabla 2.

\begin{tabular}{|c|c|c|c|}
\hline & & Frecuencia & Porcentaje \\
\hline \multirow[t]{2}{*}{ El general San Martín cruza la cordillera de los Andes para lograr la independencia de las Provincias Unidas del Río de la Plata } & De acuerdo & & 74,2 \\
\hline & En desacuerdo & 16 & 25,8 \\
\hline \multirow[t]{2}{*}{ El 9 de Julio de 1816 marca el inicio del Estado Argentino Nacional y de un país unificado } & De acuerdo & 45 & 72,6 \\
\hline & En desacuerdo & 17 & 27,4 \\
\hline La bandera Argentina fue creada por Manuel Belgrano el 20 de junio de 1820 & De acuerdo & 31 & \multirow[t]{2}{*}{$50 \%$} \\
\hline \multirow{2}{*}{ Al momento de la llegada de Cristóbal Colón a América se conquistan tierras Aztecas (Actual México) e Incas (actual Perú) } & \begin{tabular}{|l} 
En desacuerdo \\
De acuerdo
\end{tabular} & \begin{tabular}{|l|}
31 \\
31
\end{tabular} & \\
\hline & En desacuerdo & 31 & $50 \%$ \\
\hline
\end{tabular}

Premisas afirmadas entornos a hechos históricos según el total de la muestra.

Resulta significativo que el 74, 2\% y el 72, 6\% de los encuestados consideren que el cruce de los Andes se realiza para liberar a las Provincias Unidas del Río de la Plata y que el 9 de Julio de 1816 marca el inicio del Estado Nación, respectivamente. En el primer caso no se toma en cuenta que las Provincias Unidas del Río de la plata firmaron la independencia respecto de España dos años antes del cruce de los Andes (1816), quedando invisibilizado el hecho dentro del proceso de historia latinoamericana, ya que San Martin cruza los Andes para la liberación de Chile y Perú. En lo que respecta al segundo dato, como ya mencionamos, mantener esta creencia es omitir la guerra civil que sufre el territorio entre 1820 y 1860 aproximadamente, y no considerar el proceso de conformación nacional que finaliza en 1880. Por otra parte, el 50\% de la muestra considera que la Bandera Argentina fue creada el 20 de junio de 1820, cuando en realidad esa fecha se conmemora la muerte de Manuel Belgrano (creador de la Bandera) y, además, la mitad de los encuestados mantiene la creencia que la llegada de Cristóbal Colón guarda relación con las conquistas de los Imperios Inca y Azteca. Este último dato resulta preocupante considerando la importancia que se le da a la fecha en el calendario escolar, y sobre todo por el anacronismo histórico que esto genera.

\section{Discusión y conclusiones}

Los resultados analizados nos permitieron conocer que efectivamente perviven concepciones románticas y míticas en el imaginario colectivo de estudiantes y docentes del Profesorado de Educación Infantil y el Profesorado de Educación Primaria. Es posible que los primeros acercamientos a estas nociones se encuentren en el paso por su propia escuela primaria y el jardín de infantes, etapas que Carreto y López (2009) encuentran como cruciales para la comprensión de la narrativa histórica y las cuales se presentan como el momento en donde los niños aprehenden la Historia desde lo mítico y lo romántico como algo necesario.

Entre las ideas más persistentes identificamos ciertos mitos predominantes que forman parte de un imaginario nacionalista que hacen "al origen" de la Nación. A este respecto, como nos permite observar la Tabla 1, tanto la creencia de la narrativa de French y Berutti como el supuesto origen de los colores de la bandera, generan una romanización de los hechos de la semana de mayo y una omisión de la posible relación con el origen monárquico respectivamente, visibilizando lo que Carretero y Krieger (2012) sostienen respecto de que se convierte a las 
efemérides patrias en un "dispositivo identitario", creando un imaginario que se transmite como aquél "relato genealógico" de Nación que plantea Gonzales (2008), y se traduce en actos escolares de "liturgias laicas" en palabras de la autora. Estos relatos genealógicos y liturgias laicas que plantea Gonzáles comprenden concepciones idílicas de figuras como San Martín o Manuel Belgrano (Tabla 2) resaltando su heroísmo e importancia, pero generando un desconocimiento casi total de su accionar en el proceso independentista. De la misma manera, la última premisa presentada en la Tabla 2 da cuenta de aquellas figuras de la historia que se mantienen en el relato pero no son abordadas ni con profundidad ni bajo una mirada contextualizada, la idea que Colón conquistó al Imperio Azteca o Inca al llegar a América, forma parte de estos "Relatos" y "liturgias" que, como mencionan Castillo y Allori (2005), Carretero y López (2009) y Parellada (2019) siguen operando hasta nuestros días al interior de muchas escuelas argentinas si ponerse en discusión.

Los resultados de ambas tablas nos advierten de la existencia de una simplificación respecto a la declaración de independencia del 9 de Julio de 1816, gran parte de los encuestados confirman que allí nos conformamos en un estado unificado y con los límites actuales, quedando silenciado por completo el proceso histórico que lleva a la conformación del Estado Moderno. Este hecho queda teñido por esta asimilación del hito a la idea de "origen" de una Nación o de la Patria, distanciándose cada vez más de la historia disciplinar (Carretero y Kriger, 2012; Montaña y Rina, 2019). Visibilizar estos anacronismos temporo-espaciales en la historia permiten reafirmar la idea de MacMillan (2009), quien ilustra cómo la construcción del nacionalismo, de la mano del uso de la Historia, fue uno de los recursos más utilizados para la legitimación del poder político o de un Estado, proceso que se confirma en Argentina mediante los trabajos de Amuchástegui (1995), Carretero (2007), Parellada (2019), Gonzales Cuerva (2006) y Castillo y Allori (2005). Todos estos autores mencionan la ingeniaría estratégica que hay detrás del discurso propuesto en las efemérides escolares y sus rituales, los resultados arrojados en el presente estudio vislumbran que esta maquinaria es capaz de generar errores conceptuales que perduran por generaciones, tales como la creencia que San Martín realizó el histórico cruce de los Andes para nuestra independencia (tabla 2) desconociendo el plan continental latinoamericanista junto a Simón Bolívar y perdiéndose en el proceso.

Quienes trabajamos en la didáctica de las Ciencias Sociales conocemos la riqueza de trabajar la Historia desde el aspecto lúdico, desde el relato y desde aquellas experiencias que sean significativas para los niños y niñas, sin embargo, queda un gran desafío por delante: avanzar en estrategias didácticas sin simplificar ni usar irresponsablemente el discurso histórico, sin que pierda rigor científico y trasladándolo al aula de forma crítica, que permita desmontar falsos mitos e invenciones. Esa tarea requiere del profesorado en formación y en ejercicio una revisión profunda y disruptiva tanto de la propia Historia como de su didáctica. Formar futuros docentes de Historia y Ciencias Sociales debe ser un compromiso científico y público. Científico porque la Historia que se trata en las aulas escolares resulta ser en no pocas ocasiones compendios de datos repetidos y orientados hacia un fin, en no pocas ocasiones de corte romanticista o nacionalista. Pero también debe ser un compromiso público porque la Historia 
cumple una función en nuestras sociedades actuales y es la de ayudar a superar problemas de alteridad, de exclusión, persecución y aislamiento.

La presente investigación puso de relieve aquellas falsas creencias que perviven en estudiantes y docentes de profesorado de nivel Infantil y nivel Primario en la ciudad de Río Cuarto -y posiblemente en gran parte del imaginario colectivo argentino-, producto de la reproducción de un discurso histórico nacionalista anclado en los actos escolares desde el siglo XIX. Las afirmaciones y consideraciones de estudiantes de profesorado y docentes en ejercicio han visibilizado una carencia en la comprensión del proceso histórico, una descontextualización de las grandes figuras de la historia que sólo se mencionan repetidamente año tras año en los actos escolares, y nos han permitido entender el compromiso que requiere asumir la enseñanza de la historia en la formación del profesorado. Por otra parte, entendemos que las creencias de estos estudiantes y docentes no devienen de dificultades personales, sino que están íntimamente relacionadas con la influencia del currículum y de principios políticos-educativos presentes su trayectoria escolar, así como también, con la manera en que ellos aprehendieron el discurso histórico como parte de un mecanismo nacionalizador a lo largo de su formación, mediante rituales persistentes (Amuchástegui 1995; Parellada 2019).

Los resultados analizados y las conclusiones de este trabajo no buscan señalar una deficiencia en el profesorado en particular, sino que el objetivo es invitar a un cuestionamiento profundo que nos lleve a preguntarnos por qué seguimos reproduciendo los mismos discursos cuando tenemos nuevas herramientas que podrían ayudarnos a pensar diferente. Cuestionarnos como investigadores, como docentes, como ciudadanos, invitarnos a volver a pensar como niños, a no conformarnos con las primeras respuestas y a volver a la época de los “¿por qué?”. Revisemos los usos que se hacen de la Historia en los diseños curriculares y en el calendario escolar, ellos estarán siempre a la orden del día según los gobiernos de turno, busquemos nuevas formas de conmemorar y de recordar, maneras que despierten el espíritu crítico.

\section{Referencias}

Abela, A. (Coord) (2001). Las técnicas de Análisis de Contenido. Una revisión actualizada. Sevilla: Fundación Centro de Estudios Andaluces.

Abrate, L. (Coord). (2020). Informe Jurisdiccional sobre el campo de las prácticas en la formación docente inicial. Córdoba: DGES. Programa Igualdad y Calidad.

Aguilar Gavira, S. y Barroso Osuna, J. (2015). La triangulación de datos como estrategia en Investigación Educativa. Pixel Bit. Revista de Medios y Educación, 47, 73-88.

Amuchástegui, M. (1995). Los rituales patrióticos en la escuela pública. En: Puiggrós, A. (Comp.). Discursos pedagógicos e imaginario social en el peronismo (1945-1955) (13-42). Buenos Aires: Galerna.

Appleby, Hunt, J. (2000). La verdad sobre la Historia. Barcelona: Andrés Bello.

Arata, N. (2014). Efemérides. Una Oportunidad para pensar la vida en común. Buenos Aires: Mandioca.

Arteaga Castillo, B. y Camargo Arteaga, S. (2011) ¿Cómo se enseña hoy historia en las escuelas normales mexicanas? En: López Facal, R.; Velazco-Matinez, L; Santidrián Arias, V. y Armas Castro, X. (coord.) (2011). Pensar históricamente en tiempos 
de globalización. Actas I Congreso Internacional sobre enseñanza de la historia (371-376). Disponible en https://minerva.usc.es/xmlui/handle/10347/8817

Billig, M. (1998). El Nacionalismo banal y la reproducción de la identidad nacional. Revista Mexicana de Sociología, 60(1), 37-57.

Carretero, M. (2007). Documentos de Identidad. Buenos Aires: Paidós.

Carretero, M. (2019). Historia y Conmemoraciones. IBER. Didáctica de Las Ciencias Sociales, Geografia e Historia, 97, 4-7.

Carretero, M. y Kriger, M. (2012). Enseñanza de la historia e identidad nacional a través de las efemérides escolares. En Carretero, M. y Castorina, J. A. (2012). La construcción del Conocimiento Histórico (57-80). Buenos Aires: Paidós.

Carretero, M. y López Rodríguez, C. (2009) Estudios cognitivos sobre el conocimiento histórico: aportaciones para la enseñanza y alfabetización histórica. Enseñanza de las ciencias sociales: revista de investigación, 8, 75-89.

Castillo, S. L. y Allori, A. (2005). Los actos escolares como prácticas rituales: ¿conservar o redefinir? Educación, Lenguaje y Sociedad, 3, 197-206.

Citron S. (2017). Le mythe national, l'histoire de France revisitée. Paris: Éditions de l'Atelier.

Citron, S. (1984). Enseignel'Histoire aujourd'hui. La memorieperdue et retrouvée. Paris: Les editions ouvriéres.

Cock, L. y Meyran, R. (2017). Paniques identitaires. Identité(s) et idéologie(s) au prisme des sciencias sociales. Vulaines-sur-Seine: Éditions du Croquant.

Davini, C. (2015). La formación de la Práctica Docente. Buenos Aires: Paidós.

De Baets, A. (2013). A theory of the abuse of History. Revista Brasileira de História, 33(65), 17-58.

Egan, K. (1997). The educated mind. Chicago: University of Chicago Press.

Ferro, M. (1981). Cómo se cuenta la Historia a los niños del mundo entero. México: FCE.

Gómez Carrasco, C. J. y Miralles Martínez, P. (2017). Los espejos de Clío: usos y abusos de la historia en el ámbito escolar. Madrid: Sílex.

González Cuerva, R. (2006). La enseñanza de la historia para la construcción nacional Argentina (1853-1955). IBBER. Didáctica de las Ciencias Sociales, Geografia e Historia, 48, 18-33.

González, M P. (2008). Memoria, historia reciente y escuela. Notas sobre el caso argentino. IBBER. Didáctica de las Ciencias Sociales, Geografia e Historia, 55, 54-62.

Guidi Castañeda, F. (2015). La relación entre historia escolar e historia académica: estudio de caso de actos escolares del 9 de Julio. Acta de las VI Jornadas de la División Historia - III Taller de Historia Regional Homenaje al Doctor Rogelio Paredes. Luján, UNLu.

Guillen, I. (2008). Los rituales escolares en la escuela pública argentina. Revista Avá, 12, 137-154.

Hunt, L. (2019). Historia: ¿Por qué importa? Madrid: Alianza.

Macmillan, M. (2009) [2014]. Usos y abusos de la Historia. Barcelona: Ariel.

Mejía, S. (2007). Las historias de Bartolomé Mitre: operación nacionalista al gusto de los argentinos. Historia critica, 33, 98-121.

Miralles, P. y Gómez. C. (2017). Enseñanza de La Historia. Análisis de Libros de Texto y Construcción de Identidades Colectivas. Historia y Memoria de La Educación, $0(6), 9-28$. 
Montaña, J. L. de la y Rina, C. (2019). El nacionalismo banal en el profesorado de Educación Infantil y Primaria en formación y la enseñanza-aprendizaje de la Historia. Perfiles Educativos, XI.I (165), 96-113.

Parellada, C. (2019). Efemérides en las escuelas de Argentina América Latina: Sociedades y territorios en los inicios del siglo XXI. Iber.Didáctica de las Ciencias Sociales, Geografia e Historia, 97, s/d.

Pérez Garzón, J. (2007). La geografía y la historia, en la encrucijada de las identidades. En Cohen Amselem, A. y Peinado Santaella, R. G. (coord.). Historia, historiografia y Ciencias Sociales (149-174). Granada: EUG.

Quezada, M. (2009). Las ceremonias cívicas escolares como ritos identitarios. Revista Latinoamericana de Estudios Educativos, XXXIX (1-2), 193-233.

Tertrais, B. (2017). La revanche de l'histoire. París: Odiel Jacob.

Troulliot, M. (2017). Silenciando el pasado. El poder y la reproducción de la Historia. Granada: Comares Historia. 